\title{
DEVISING RESEARCH INQUIRIES: AN INTERDISCIPLINARY-STRATEGIC APPROACH
}

Alen Badal'

Independent Researcher, Modesto, United States of America

\section{ABSTRACT}

At the core of a successful research is the inquiry process to attain knowledge about the problem, to address the overarching research question and any sub-components. Research methodology processes take form in numerous ways, such as, but not limited to, question-based, archive analysis and observation, among others. Queries illuminate the path to reaching a level of core understanding, as a result of assimilating the results of the inquiry process, either by way of research questions and/or review of documents and observations. The intent of this article is to highlight a strategic approach to devising research inquiries from an interdisciplinary perspective.

\section{JEL CLASSIFICATION \& KEYWORDS}

- M10 = INTERDISCIPLINARY - RESEARCH - QUALITATIVE QUANTITATIVE RESEARCH QUESTIONS M MIXEDMETHODS — STRATEGIC MANAGEMENT

\section{INTRODUCTION}

Not to be misled, the objective of this work is to identify an interdisciplinary methodology of devising research/survey questions for a research initiative, to squarely help address an overarching research inquiry, borrowing methodology from the David's (2013) strategic analyses methods. The process may be used to frame an overarching research question if one is backward-designing. The focus is on methods to writing research questions to solicit for responses in order to serve as data for analysis.

\section{Discussion}

The strategic process applied to survey question development is a process that is rather simple, yet, requiring a greater degree of initial inquiry and research to develop. The method for understanding the core of a topic in strategic management is to conduct an internal and external analysis. On the surface, the process is the same when devising a research inquiry in research where a researcher typically may write questions revolving around the research question. What may serve as a limitation is the quality and vantage points of the queries. To best understand a critical inquiry often requires looking at the issues from both inside and outside of the parameters, inter-disciplinarily. Too often inquiries and problems are not one-dimensional and are abstract, requiring an in-depth understanding to support/address. This article will bridge a strategic concept of analysis with the survey research question writing process.

Following an internal/external analysis model described by Fred David (2013) in his textbook entitled Strategic Management Concept and Cases, the process involves researching and collecting information on particular strengths, weaknesses, opportunities and threats associated with a research focus. This is conventionally known in business as a "SWOT" analysis. However, taking

' abadal3@aol.com

www.journals.cz it a step further and applying it to the formulation of clear and complete research questions for a qualitative, quantitative, or mixed-study is the contribution of this work bridging the process of conducting an internal and external analysis to develop research questions all the while interdisciplinarilly thinking.

A conventional SWOT analysis focuses on just those: the strengths, weaknesses, opportunities, and threats. A step deeper in analysis begs for an individual or organization to understand a synthesis of such steps. What and/or how can we utilize our strengths to take advantage of opportunities? Or, how do our weaknesses affect current or future threats affecting our situation? How can we use our weaknesses to avoid further damage which may result from threats affecting us? The internal analysis involves a researcher collecting data as to the strengths and weaknesses of an organization to synthesize with the collection of data representing the opportunities and threats, known as the external analysis, affecting an organization (or department/unit/individuals). The matching process to analyze the internal/external factors requires analysis of the following collecting of data.

\section{Formulating Research Questions}

To begin the process, the researcher's intent shall be to write questions to beg for thought and consideration of subjects being presented the questions. Specifically, one shall pose questions to have subjects consider their perceived strengths, weaknesses, opportunities and threats affecting their organization or themselves. The task of the researcher is not be biased and provide solutions, but simply to pose questions for a deeper level of analysis of subjects.

The intent of questioning with the right questions is to provide an opportunity for subject(s) to consider vantage points when responding. It may be one has not yet considered how to use their strengths to heed possible threats without being probed to think critically, 360-degrees. At the conclusion of questioning and collection of data would help the researcher to have some level of understanding in order to analyze responses and understand the research exploration/inquiry. One example may be the following:

Problem Statement: Some used car dealers in ABC City have closed their doors claiming sales have plummeted.

In the example above, the purpose of research may be to identify why some used car businesses in ABC City have been closing. The overarching research question may be to understand why used car dealers in ABC City have been closing or what strategies to consider in order to remain in business.

To begin the process the researcher shall begin to pose four questions simply focusing on identification and reasoning as to strengths, weaknesses, opportunities and threats. Following shall be questions posed on utilization of the internal analysis (strengths \& weaknesses) against external factors/analysis (opportunities \& threats). Sample posed questions shall include: 


\section{Internal Analysis (two open-ended examples)}

1. Please share the strengths you/your organizations possesses and what constitutes their status representing a strength?

2. Please share what weaknesses you believe you/your organization possesses and what constitutes the classification of being a weaknesses?

\section{External Analysis (examples)}

3. What opportunities do you believe exist that you may utilize your strengths to capture?

4. What threats do you believe affect you/your organization where your current strengths may help avoid?

Internal Analysis (two Likert scale examples)

1. I/we consider our strengths when business planning? (1-disagree; 2-somewhat disagree; 3-neutral; 4-some what agree; 5-strongly agree)

2. I/we feel we can reduce and/or eliminate our weaknesses based on applying our strength(s)? (1-disagree; 2-somewhat disagree;3-neutral; 4-somewhat agree; 5-strongly agree)

\section{External Analysis (examples)}

3. Please rate the importance of using your strengths to take advantage of opportunities. (1-not important; 2-somewhat important; 3-important; 4-very important; 5-unsure/don't know)

4. How familiar do you think you/your organization is with analyzing external factors, (such as threats \& opportunities) which may or may not affect your business? (1-no familiar; 2-somewhat familiar; 3-familiar; 4-very familiar; 5-unsure/don't know).

The process enables respondents to provide responses and really self-analyze the problem from a distinct vantage point. It's important for a researcher, when writing research questions, to pose questions from an interdisciplinary standpoint. Specifically, when writing external analysis types of questions to consider the industry the problem is associated with along with external factors affecting the industry, for example. As previously noted, most problems are intrinsically interdisciplinary in nature and require a multi-faceted approach and analysis to best identify strategies to resolve.

The researcher shall remain neutral and not provide data, but pose the right questions to solicit for specific analysis and data/responses, which then represents as valuable data for the researcher to analyze in order to address the overarching research inquiry. In such cases will assist stakeholders to think interdisciplinary. Specifically, consider all fields when devising questions. For example, when working on an education problem/research it's important to consider the fields of psychology, business, sociology, etc. When studying a business problem, it is critical to consider fields, such as education, sociology, economics, public policy, etc. Analysis may take many forms when formulating questions; an adapted illustration is noted, below, stemming from the work of Fred R. David (see Table 1, below).

Any combination of internal/external analyses/combining may prove insightful for ultimate data analysis. Specifically, interdisciplinary fields, such as sociology, psychology, economics, and history, among other fields may provide insight into human intellect, organizational behavior, historical events in the world and metrics. The data analysis process may include qualitative and quantitative data, where possible sequences may be qualitative-quantitative or www.journals.cz

\begin{tabular}{|l|l|}
\hline \multicolumn{2}{|l|}{ Table 1: Analyses Considerations } \\
\hline Internal Analysis & Opportunities \\
\hline Strengths & Threats \\
\hline Weaknesses & Opportunities-Threats \\
\hline Internal/External Synthesizing & \\
\hline Strengths-Opportunities & Weaknesses-Threats \\
\hline Strengths-Threats & \\
\hline Weaknesses-Opportunities & \\
\hline Source: David (2013) & \\
\hline
\end{tabular}

visa-versa (Venkatesh, Brown \& Sullivan, 2016). In analyses, matching is not without limitation, such as criteria and/or sample size, for example (Bettis, Gambardella, Helfat, \& Mitchell, 2014). To best be able to contribute thought and consideration in the formulation process, it is recommended to have input from professionals with backgrounds in various fields.

Sample interdisciplinary inquiries:

1. What effects does understanding sociological cultures have on the current challenge(s)? (Sociology)

2. How sensitive are we with our professional relationships with stakeholders? (Organizational behavior)

3. How much do we value intellectual contributions and more importantly demonstrate contributions are considered/implemented? (Psychology)

4. Historically, what have been the outcomes of our business strategies and success factors? (History)

5. Optimally, what effects have our strategies and functions have had on our financial stance? (Economics)

\section{CONCLUSION}

In sum, the formulation of appropriate research questions for instruments and surveys is critical in soliciting for data used for analysis to address the research inquiry. Additionally, problems may not be linear; thereby, may be benefitting being analyzed from an interdisciplinary, 360-degree approach. Roberts and Stockport (2009) share 'organization flexibility' being an organization's ability to manage risk by way of responding to opportunities and threats. This is yet another vantage point in data analysis. The approach of questioning utilizing a strategic management Internal/External analyses (David, 2013) may help frame inquiries to solicit for data from various vantage points. According to Hammoud \& Nash, (2014) internal/external data is critical in market conditions that are 'static.' The intend of this article is to articulate a strategic approach to devising research inquiries drawing from Fred R. David's (2013). Internal/External analyses select methodologies to help formulate questions ranging and inclusive of interdisciplinary fields. The interdisciplinary thinking in research inquiry formulation is the contributory intent of this article to interdisciplinary fields in research.

\section{REFERENCES}

Bettis, R., Gambardella, A., Helfat, C., \& Mitchell, W. (2014). Quantitative empirical analysis in strategic management. Strategic Management Journal, 35, 949-953. DOI:10.1002/smj.2278

David, F. R. (2013). Strategic management: Concepts and cases. Upper Saddle River, NJ: Prentice Hall.

Hammoud, M. S., \& Nash, D. P. (2014). European Journal of Futures Research, 2(1), 1-20. DOI: 10.1007/s40309-014-0042-9 
Roberts, N., \& Stockport, G. (2009). Defining strategic flexibility. Global Journal of Flexible Systems Management, 10(1), 27-32. Retrieved from http://search.proquest.com.ezp.waldenulibrary.org/ docview/201708023?accountid $=14872$

Venkatesh, V., Brown, S. A., \& Sullivan, Y. W. (2016). Guidelines for conducting mixed-methods research: An extension and illustration. Journal of the Association for Information Systems, 17(7), 435-495. Retrieved from http://aisel.aisnet.org/jais/vol17/iss $7 / 2$ 